УДК 331.544

ББК 65.240

DOI $10.31554 / 2222-9175-2018-30-123-130$

Ю. Г. Бюраева, Н. А. Бабуева

УРОВЕНЬ ТРУДОУСТРОЙСТВА ВЫПУСКНИКОВ ВУЗОВ

КАК ПОКАЗАТЕПЬ КАЧЕСТВА ВЫСШЕГО

ПРОФЕССИОНАПЬНОГО ОБРАЗОВАНИЯ (на данных по Респубпике Бурятия)

Оценивается качество высшего образования по результатам мониторинга трудоустройства выпускников образовательных учреждений высшего профессионального образования в Республике Бурятия. Приведены и проанализированы данные в целом по Сибирскому федеральному округу, высшим учебным заведениям Республики Бурятия и в разрезе отдельных специальностей/направлений подготовки. Рассмотрены проблемы и перспективы трудоустройства выпускников.

Ключевые слова: высшее профессиональное образование, качество образования, мониторинг, уровень трудоустройства выпускников, рынок труда, востребованные специальности.

Yu. G. Byuraeva, N. A. Babueva

\title{
EMPLOYABILITY LEVEL OF UNIVERSITY GRADUATES AS A QUALITY INDICATOR OF HIGHER PROFESSIONAL EDUCATION (Based on Data from the Republic of Buryatia)
}

In this paper the authors carry out quality of higher education assessment based on the results of employability monitoring of graduates of institutions of higher professional education in the Republic of Buryatia. They provide and analyze data for the Siberian Federal District in general, higher educational institutions of the Republic of Buryatia, and by separate majors / training programs. The paper also considers employment problems and prospects for the graduates.

Keywords: higher professional education, quality of education, monitoring, employability level of graduates, job market, demanded specialities.

$\Pi^{\circ}$ остановка проблемы

Развитие кадрового потенциала способствует повышению эффективности экономики и конкурентоспособности региона в целом, для чего необходимо соответствующее функционирование системы профессионального образования, важнейшей характеристикой которого является его качество.

Обеспечение качества образования, отвечающего потребностям рынка труда, входит в число главных задач органов управления образованием федерального и регионального уровня. В настоящее

БЮРАЕВА Юлия Григорьевна - доктор социологических наук, ведущий научный сотрудник отдела региональных экономических исследований Федерального государственного бюджетного учреждения науки «Бурятский научный центр СО РАН» (Улан-Удэ, Россия). Е-mail: julbur@yandex.ru.

БАБУЕВА Нина Анатольевна - ведущий экономист отдела региональных экономических исследований Федерального государственного бюджетного учреждения науки «Бурятский научный центр СО РАН» (Улан-Удэ, Россия). E-mail: orei.bnc@mail.ru. 
время один из подходов к его оценке основан на системе всероссийского и регионального мониторинга качества образования. При этом правительством РФ особое внимание придается трудоустройству выпускников по полученной специальности, подтверждением чему служит его включение в качестве порогового показателя эффективности учреждений высшего образования.

Целью данной статьи является оценка качества высшего образования Республики Бурятия на основе исследования уровня трудоустройства выпускников региональных вузов. Предполагается, что наиболее значимым критерием оценки качества образования является уровень трудоустройства выпускников, их востребованность на рынке труда. Чем выше уровень их трудоустройства, тем эффективнее использование бюджетных средств. Эмпирической базой исследования послужили данные мониторинга трудоустройства выпускников Министерства образования РФ [Мониторинг...], Бурятстата, Республиканского агентства занятости населения и сведения отделов по содействию трудоустройству вузов Республики Бурятия (РБ). Данная статья является продолжением исследования уровня трудоустройства выпускников в разрезе образовательных учреждений и специальностей. На предыдущем этапе оценивалось качество среднего профессионального образования Республики Бурятия [Бюраева 2017].

\section{Динамика численности студентов системы ВПО}

Необходимо отметить постоянное снижение численности студентов, обучающихся по программе высшего профессионального образования как в РФ в целом, так и в Бурятии в частности. Если в 2010 г. их численность в РФ составляла 7049,8 тыс. чел., то в 2016 г. - уже 4399,5 тыс. (-37,6 \%), в РБ - 48,2 тыс. и 28,7 тыс. соответственно $(-40,4 \%)$ [Регионы... 2017]. Это связано, прежде всего, со снижением числа абитуриентов в целом по РФ более чем в 10 раз за последние 10 лет вследствие спада рождаемости в 1990-е гг. Также наблюдается сокращение количества вузов, в основном частных. С 2016 по 2017 г. прекратили свою деятельность 52 вуза, 50 из которых являлись частными.

Кроме того, в Республике Бурятия более четверти выпускников школ уезжают учиться в другие регионы. Конкуренция со стороны нереспубликанских вузов РФ возрастает, что стало следствием введения ЕГЭ и упрощения процедуры приема. Также численность выпускников в центральных регионах России меньше, чем в Восточной Сибири, из-за более низкого уровня рождаемости. При этом число бюджетных мест в ведущих вузах увеличивается или остается на прежнем уровне, а в Бурятии оно ежегодно сокращается. Исключение составляет медицинский факультет БГУ, который планирует увеличение числа бюджетных мест.

Таблица 1

Уровень трудоустройства выпускников вузов СФО, \%

\begin{tabular}{|l|c|c|c|}
\hline \multicolumn{1}{|c|}{ Регион } & 2014 г. & 2015 г. & 2016 г. \\
\hline Республика Алтай & 65 & 65 & 65 \\
\hline Республика Бурятия & 70 (10-е место) & 70 (10-е место) & 65 (12-е место) \\
\hline Республика Тыва & 45 & 70 & 70 \\
\hline Республика Хакасия & 75 & 75 & 80 \\
\hline Алтайский край & 75 & 75 & 75 \\
\hline Забайкальский край & 65 & 60 & 75 \\
\hline Красноярский край & 75 & 75 & 75 \\
\hline Иркутская область & 75 & 75 & 75 \\
\hline Кемеровская область & 80 & 80 & 75 \\
\hline Новосибирская область & 80 & 80 & 80 \\
\hline Омская область & 75 & 80 & 80 \\
\hline Томская область & 80 & 85 & 70 \\
\hline Пороговое значение для СФО & 75 & 75 & \\
\hline
\end{tabular}






Рис. Трудоустройство выпускников вузов РБ, \%

Характеристика трудоустройства выпускников

Анализ данных мониторинга Министерства образования РФ выявил несоответствие уровня трудоустройства выпускников в Республике Бурятия пороговому значению, установленному для вузов СФО. Доля трудоустроенных выпускников 2014-2016 гг., следующих за годом выпуска, составила 65-70 \%, что на $5 \%$ ниже нормативного показателя (табл. 1). Этот показатель был ниже и среднего показателя по СФО (в 2014 г. $72 \%$, в 2015 г. - $74 \%$, в 2016 г. - $75 \%$ ).

Наблюдается негативная тенденция снижения уровня трудоустройства выпускников вузов РБ. Так, в 2013 г. средний уровень трудоустройства выпускников составлял $95 \%$, а в 2015 г. - $65 \%$ (рис.). В 2013 г. отклонение от порогового значения составляло $3 \%$, в 2015 г. - $10 \%$.

В системе профессионального образования наибольшую долю в подготовке кадров занимают три вуза республики - ВСГУТУ, БГУ и БГСХА. На их долю приходится соответственно 30,3, 30,7 и $18,7 \%$ от всего контингента студентов в Республике Бурятия (табл. 2).

Можно заключить, что количество выпускаемых ежегодно специалистов значительно превышает потребности организаций в Республике Бурятия в квалифицированных специалистах высшего профессионального образования [Распоряжение ...]. Так, по направлению подготовки «экономика и управление» заявленная органами государственной власти РБ потребность в кадрах высше- го профессионального образования в 2016 г. составляла 121 человек, а вузами было подготовлено 1861 выпускник; по направлению «юриспруденция» потребность составляла 10 человек - выпущено 642 специалиста. Такой дисбаланс спроса и предложения наблюдается по большинству направлений подготовки. Это связано в первую очередь с тем, что в настоящее время при поступлении в образовательные организации абитуриенты недостаточно ориентированы на востребованность специальностей экономикой и рынком труда региона. Наибольшая привлекательность выбранной профессии, по их мнению, заключается в престижности профессии, высокой заработной плате, карьерном росте. Только треть учащихся общеобразовательных организаций ориентируются при выборе будущей профессии на критерий реального спроса на региональном рынке труда.

\section{Структура подготовки кадров}

Трудоустройство выпускников различается в зависимости от направления подготовки. Как видно из таблицы 3, выпускники одних специальностей хорошо трудоустраиваются или повышают свой образовательный уровень в учебном заведении следующей ступени. Выпускники других специальностей испытывают большие сложности с трудоустройством. Так, самый высокий процент трудоустройства у выпускников, окончивших инженерные и медицинские направления подготовки, а также в сфере образования, культуры и искусства. 
Таблица 2

Роль вузов РБ в системе подготовки кадров для региона по итогам 2016 г.*

\begin{tabular}{|c|c|c|c|c|c|c|c|c|}
\hline \multirow[b]{2}{*}{$\begin{array}{c}\text { Направление } \\
\text { (отрасль науки) }\end{array}$} & \multicolumn{2}{|c|}{ ВСГУТУ } & \multicolumn{2}{|c|}{ БГУ } & \multicolumn{2}{|c|}{ БГСХА } & \multicolumn{2}{|c|}{ ВСГИК } \\
\hline & $\begin{array}{l}\text { Кол- } \\
\text { во, } \\
\text { чел. }\end{array}$ & $\begin{array}{c}\text { Доля от } \\
\text { общего } \\
\text { числа } \\
\text { обучаю- } \\
\text { щихся в } \\
\text { РБ, \% }\end{array}$ & $\begin{array}{l}\text { Кол- } \\
\text { во, } \\
\text { чел. }\end{array}$ & $\begin{array}{c}\text { Доля от } \\
\text { общего } \\
\text { числа } \\
\text { обучаю- } \\
\text { щихся в } \\
\text { РБ, \% }\end{array}$ & $\begin{array}{l}\text { Кол- } \\
\text { во, } \\
\text { чел. }\end{array}$ & $\begin{array}{c}\text { Доля от } \\
\text { общего } \\
\text { числа } \\
\text { обучаю- } \\
\text { щихся в } \\
\text { РБ, \% }\end{array}$ & $\begin{array}{l}\text { Кол- } \\
\text { во, } \\
\text { чел. }\end{array}$ & $\begin{array}{c}\text { Доля от } \\
\text { общего } \\
\text { числа } \\
\text { обучаю- } \\
\text { щихся в } \\
\text { РБ, \% }\end{array}$ \\
\hline $\begin{array}{l}\text { Математические } \\
\text { и естественные } \\
\text { науки }\end{array}$ & 116 & 9,5 & 1055 & 86,8 & 45 & 3,7 & 0 & 0 \\
\hline $\begin{array}{l}\text { Инженерное } \\
\text { дело, технологии } \\
\text { и технические } \\
\text { науки }\end{array}$ & 2958 & 72,5 & 314 & 7,7 & 464 & 11,4 & 25 & 0,6 \\
\hline $\begin{array}{l}\text { Здравоохранение } \\
\text { и медицинские } \\
\text { науки }\end{array}$ & 0 & 0 & 857 & 100 & 0 & 0 & 0 & 0 \\
\hline $\begin{array}{l}\text { Сельское хозяйство } \\
\text { и сельскохо- } \\
\text { зяйственные науки }\end{array}$ & 120 & 8,1 & 0 & 0 & 1357 & 91,9 & 0 & 0 \\
\hline $\begin{array}{l}\text { Науки об } \\
\text { обществе }\end{array}$ & 1749 & 34,3 & 2182 & 42,7 & 668 & 13,1 & 82 & 1,6 \\
\hline $\begin{array}{l}\text { Образование } \\
\text { и педагогические } \\
\text { науки }\end{array}$ & 0 & 0 & 528 & 93,1 & 19 & 3,3 & 20 & 3,6 \\
\hline $\begin{array}{l}\text { Гуманитарные } \\
\text { науки }\end{array}$ & 5 & 0,6 & 839 & 99,4 & 0 & 0 & 0 & 0 \\
\hline $\begin{array}{l}\text { Искусство } \\
\text { и культура }\end{array}$ & 50 & 6 & 0 & 0 & 0 & 0 & 779 & 94 \\
\hline $\begin{array}{l}\text { Доля от всего } \\
\text { контингента } \\
\text { студентов в РБ, \% }\end{array}$ & & 30,3 & & 0,7 & & 8,7 & & 8,1 \\
\hline
\end{tabular}

* Кроме филиалов вузов и вузов, находящихся в стадии реорганизации/реорганизованных или не выполнивших 4 или более показателей, по которым осуществляется подтверждение прохождения мероприятий по государственному контролю (надзору) в сфере образования за деятельностью организации по результатам мониторинга 2016 г.

Это стало следствием несоответствия структуры подготовки специалистов с высшим образованием требованиям рынка труда. Наибольший удельный вес занимает специальность «экономика и управление» - 27,4 \% от общей численности выпускников. Также можно выделить специальности «юриспруденция» $9,5 \%$, «сельское, лесное и рыбное хозяйство» $-5,3$ \% и т. д., их трудоустройство находится на низком уровне. Например, по направлению «юриспруденция» трудоустроились 57 \% выпускников, «сельское, лесное и рыбное хозяйство» $-51 \%$.

При этом наиболее востребованными на рынке труда в 2016 г. были спе- циалисты, прошедшие обучение по направлениям подготовки «клиническая медицина» - 38,5 \% от заявленной работодателями потребности в работниках высшего уровня квалификации, «образование и педагогические науки» - 23,9 \%, а также специалисты в области гуманитарных наук и культуры - 15,7 \% [Сведения...]. Как следует из таблицы 3, доля трудоустроенных выпускников по этим специальностям составляла 80-94 \%, несмотря на ежегодное увеличение числа выпускников. Так, в 2016 г. специалистов в области клинической медицины было подготовлено в 2,2 раза больше, чем в 2014 г., фармации - в 9,3 раза, музыкаль- 
Таблица 3

Трудоустройство выпускников по группам направлений подготовки

(в последующий год после выпуска)

\begin{tabular}{|c|c|c|c|c|}
\hline \multirow[b]{2}{*}{$\begin{array}{c}\text { Укрупненная группа специальностей/ } \\
\text { направлений подготовки }\end{array}$} & \multicolumn{2}{|c|}{2014 г. } & \multicolumn{2}{|c|}{2016 г. } \\
\hline & $\begin{array}{c}\text { Численность } \\
\text { выпускни- } \\
\text { ков, чел. }\end{array}$ & $\begin{array}{c}\text { Доля } \\
\text { трудо- } \\
\text { устроен- } \\
\text { ных, \% }\end{array}$ & $\begin{array}{c}\text { Числен- } \\
\text { ность } \\
\text { выпускни- } \\
\text { ков, чел. }\end{array}$ & $\begin{array}{c}\text { Доля } \\
\text { трудо- } \\
\text { устроен- } \\
\text { ных, \% }\end{array}$ \\
\hline Математика и механика & 369 & 77 & 48 & 67 \\
\hline Компьютерные и информационные науки & 9 & 44 & 30 & 60 \\
\hline Физика и астрономия & 27 & 48 & 25 & 60 \\
\hline Химия & 9 & 56 & 15 & 60 \\
\hline Науки о земле & 70 & 54 & 81 & 47 \\
\hline Биологические науки & 29 & 66 & 58 & 57 \\
\hline Техника и технологии строительства & 209 & 71 & 208 & 65 \\
\hline Информатика и вычислительная техника & 155 & 79 & 207 & 64 \\
\hline Электроника, радиотехника и системы связи & 143 & 69 & 157 & 54 \\
\hline $\begin{array}{l}\text { Фотоника, приборостроение, оптические } \\
\text { и биотехнические системы и технологии }\end{array}$ & 13 & 62 & 19 & 84 \\
\hline Электро- и теплоэнергетика & 205 & 71 & 191 & 65 \\
\hline Машиностроение & 100 & 77 & 143 & 73 \\
\hline Химические технологии & 13 & 69 & 17 & 59 \\
\hline Промышленная экология и биотехнологии & 151 & 77 & 151 & 72 \\
\hline $\begin{array}{l}\text { Техносферная безопасность } \\
\text { и природообустройство }\end{array}$ & 94 & 77 & 171 & 44 \\
\hline $\begin{array}{l}\text { Прикладная геология, горное дело, } \\
\text { нефтегазовое дело и геодезия }\end{array}$ & 26 & 69 & 142 & 45 \\
\hline Технологии материалов & 14 & 43 & 24 & 50 \\
\hline Техника и технологии наземного транспорта & 87 & 70 & 57 & 56 \\
\hline Авиационная и ракетно-космическая техника & 7 & 100 & 8 & 88 \\
\hline Управление в технических системах & 67 & 81 & 61 & 72 \\
\hline Технологии легкой промышленности & 41 & 68 & 48 & 52 \\
\hline Клиническая медицина & 81 & 80 & 177 & 90 \\
\hline Фармация & 7 & 71 & 65 & 94 \\
\hline Сельское, лесное и рыбное хозяйство & 25 & 68 & 360 & 51 \\
\hline Ветеринария и зоотехния & 16 & 44 & 99 & 57 \\
\hline Психологические науки & 129 & 78 & 24 & 63 \\
\hline Экономика и управление & 2344 & 74 & 1861 & 70 \\
\hline Социология и социальная работа & 86 & 67 & 144 & 67 \\
\hline Юриспруденция & 1061 & 61 & 642 & 57 \\
\hline Политические науки и регионоведение & 78 & 53 & 79 & 42 \\
\hline $\begin{array}{l}\text { Средства массовой информации } \\
\text { и информационно-библиотечное дело }\end{array}$ & 95 & 62 & 114 & 60 \\
\hline Сервис и туризм & 121 & 73 & 142 & 61 \\
\hline Образование и педагогические науки & 378 & 81 & 469 & 80 \\
\hline Языкознание и литературоведение & 172 & 70 & 124 & 72 \\
\hline История и археология & 66 & 74 & 60 & 53 \\
\hline Философия, этика и религиоведение & 5 & 100 & 12 & 67 \\
\hline Физическая культура и спорт & 137 & 64 & 112 & 52 \\
\hline Искусствознание & 9 & 89 & 2 & 50 \\
\hline Культуроведение и социокультурные проекты & 356 & 75 & 321 & 76 \\
\hline $\begin{array}{l}\text { Сценические искусства и литературное } \\
\text { творчество }\end{array}$ & 15 & 93 & 47 & 81 \\
\hline Музыкальное искусство & 10 & 90 & 24 & 92 \\
\hline Изобразительное и прикладные виды искусств & 24 & 54 & 43 & 51 \\
\hline
\end{tabular}


ного искусства - в 2,4 раза, образования - в 1,2 раза.

В 2016 г. средний процент трудоустройства всех выпускников вузов в РБ был на уровне 70, что соответствует пороговому значению в СФО. Средний размер заработной платы выпускников составил 24281 руб. В лидеры по заработной плате вышли выпускники УУИЖТ - филиала ИРГУПС (39058 руб.) и БГУ (24388 руб.). Наиболее востребованными стали выпускники филиалов вузов в РБ: Бурятского филиала СибУПК - 80 \% трудоустроенных, Байкальского филиала Гуманитарного института, БИИК СибГУТИ - по 75 \%. Также выше порогового значения оказалась доля трудоустроенных выпускников ВСГИК - 75 \%. Остальные республиканские вузы показали отрицательные результаты. Худший результат у БГСХА - 60 \% (табл. 4).

Это связано, в первую очередь, со стагнацией в сфере сельского хозяйства. Одним из факторов, влияющим на низкую долю трудоустроенных выпускников основных вузов РБ, может быть отсутствие какого-либо опыта работы, тогда как выпускники филиалов иногородних вузов в основном обучаются заочно и уже имеют определенный опыт работы или работают по специальности. Также негативные показатели могут свидетельствовать о падении престижности вузов республики для абитуриентов.

\section{Выводы и предложения}

Уменьшение контингента студентов приведет к сокращению учреждений профессионального образования, если не будут найдены компенсирующие формы, в т. ч. учебной миграции из соседних регионов. При высокой востребованности высшего образования снизится спрос на учреждения среднего профессионального образования.

Как и в других регионах Российской Федерации, в Республике Бурятия существует проблема «популяризации» высшего образования, что ведет к появлению на рынке труда невостребованных специалистов, испытывающих трудности с поиском рабочих мест. Некоторые специальности становятся невостребованными вследствие как низкого качества образования, так и ограниченности их применения на рынке труда республики.

Кроме того, если бюджетный набор ограничен государственным финансированием и контрольными цифрами приема, то прием на коммерческой основе строго не ограничен. Вузы более заинтересованы в привлечении дополнительного контингента и получении доходов от

Таблица 4

Трудоустройство выпускников в разрезе вузов Республики Бурятия в 2016 г.

(выпуск 2015 г.)

\begin{tabular}{|l|c|c|c|}
\hline \multicolumn{1}{|c|}{ Вуз } & $\begin{array}{c}\text { Число } \\
\text { выпускников } \\
\text { чел. }\end{array}$ & $\begin{array}{c}\text { Средняя заработ- } \\
\text { ная плата, руб. }\end{array}$ & $\begin{array}{c}\text { Доля } \\
\text { трудоустройства, } \\
\%\end{array}$ \\
\hline ВСГУТУ & 2578 & 23749 & 65 \\
\hline БГУ & 2027 & 24388 & 65 \\
\hline БГСХА им. В. Р. Филиппова & 1231 & 23334 & 60 \\
\hline ВСГИК & 684 & 20195 & 75 \\
\hline $\begin{array}{l}\text { БФ ННОУ ВПО Гуманитарный } \\
\text { институт (г. Москва) }\end{array}$ & 39 & 20447 & 70 \\
\hline $\begin{array}{l}\text { Улан-Удэнский институт железно- } \\
\text { дорожного транспорта - филиал } \\
\text { ФГБОУ ВПО ИрГУПС иноком- }\end{array}$ & 35 & 39058 & 75 \\
\hline $\begin{array}{l}\text { Бурятский институт инфоко } \\
\text { муникаций (филиал) ФГБОУ ВО } \\
\text { СибГУТИ }\end{array}$ & 81 & 23884 & 80 \\
\hline $\begin{array}{l}\text { БФ ЧОУ ВПО Центросоюза РФ } \\
\text { Сибирский университет } \\
\text { потребительской кооперации }\end{array}$ & 50 & 19195 & 75 \\
\hline
\end{tabular}

* По данным, направленным в ПФР и допущенным к обработке. 
оказания образовательных услуг, чем в восполнении кадров для развития экономики. Избыток специалистов, в первую очередь выпускников юридического и экономического профиля, не востребованных на рынке труда либо работающих не по специальности, приводит к неэффективному расходу бюджетных средств. Изначально ресурсы тратятся на обучение, а затем на выплаты безработным и их переобучение. В связи с этим набор на коммерческую форму обучения необходимо ограничить и создать условия для равного положения студентов независимо от формы обучения и образовательной организации. Таким образом, можно предположить эффективность таких мер, как:

- ограничение проходных баллов для поступления на коммерческую форму обучения в образовательные организации высшего образования;

- расширение практики целевого приема на обучение;

- ограничение количества мест для коммерческой формы обучения в образовательных организациях высшего образования;

- при отчислении студента за неуспеваемость ограничить возможности поступления на коммерческой основе на некоторый временной период, с возможностью понижения срока после прохождения срочной службы в армии, рождения ребенка или при наличии подписанного договора, обеспечивающего трудоустройство выпускника по окончании обучения. При этом возможность обучения в учреждениях СПО должна быть сохранена;

- прямое ценовое регулирование оплаты за обучение по невостребованным экономикой направлениям подготовки;

- рассмотрение возможности предоставления выпускникам образова- тельных организаций СПО по востребованным направлениям подготовки, проработавшим определенное время по специальности, права получения высшего образования по аналогичному направлению подготовки на бюджетной основе без вступительных испытаний.

При этом важной проблемой остается кадровый дефицит в районах республики. После окончания вуза подавляющая часть выпускников, приехавших из районов республики, не стремится к возвращению. С целью устранения данной тенденции и притока молодых специалистов в сельскую местность необходимо разработать совместно с Министерством образования и науки РБ, государственными органами РБ, администрациями муниципальных районов, вузами и организациями четкие механизмы их закрепления в организациях соответствующих населенных пунктов. Необходимо обеспечить создание условий, способствующих развитию заинтересованности в работе, проживанию на селе (достаточный уровень заработной платы, предоставление жилья, развитие социальной инфраструктуры и др.).

Для развития в Республике Бурятия образовательных организаций высшего образования, ориентированных, прежде всего, на запросы региональной экономики и рынка труда, необходимо обеспечить долгосрочное взаимодействие государственных органов, работодателей и образовательных организаций, а также поддерживать взаимодействие с выпускниками вузов в целях оценки реального положения их востребованности на рынке труда. При формировании структуры подготовки специалистов необходимо учитывать региональную стратегию развития приоритетных отраслей экономики и социальной сферы.

\section{Источники и питература}

Бюраева Ю. Г. Трудоустройство выпускников как критерий оценки качества среднего профессионального образования (на примере Республики Бурятия) / Ю. Г. Бюраева // Эко. 2017. - № 2. - С. 164-172. 
Мониторинг трудоустройства выпускников Министерства образования РФ [Электронный ресурс]. - Режим доступа: http://vo.graduate.edu.ru/\#/?year=2015\&year_monitoring=2016 (дата обращения: 18.09.2017).

Сведения о предоставлении государственных услуг в области содействия занятости населения [Электронный ресурс]. - Режим доступа: http://burzan.govrb.ru/wp-content/uploads/2015/02/2-т-РБ-за-2016-год.xls (дата обращения: 06.03.2018).

Распоряжение Главы Республики Бурятия № 37-рг от 01.07.2014 г. «Об обеспечении потребности организаций в профессиональных кадрах среднего и высшего профессионального образования и трудоустройства безработных граждан в Республике Бурятия».

Регионы России. Социально-экономические показатели. 2017: Стат. сб. / Росстат. - М., 2017. - C. $344-442$.

\section{References}

Byuraeva Yu. G. Trudoustroystvo vyipusknikov kak kriteriy otsenki kachestva srednego professionalnogo obrazovaniya (na primere Respubliki Buryatiya) [Employment of graduates as a criterion for assessing the quality of secondary vocational education (on the example of the Republic of Buryatia)] / Yu. G. Byuraeva // Eko. - 2017. - No. 2. - P. 164-172.

Monitoring trudoustroystva vyipusknikov Ministerstva obrazovaniya RF [Monitoring of employment of graduates of the Ministry of education of the Russian Federation]. Available at: http:// vo.graduate.edu.ru/\#/?year=2015\&year_monitoring=2016 (accessed 18.09.2017).

Svedeniya o predostavlenii gosudarstvennyih uslug v oblasti sodeystviya zanyatosti naseleniya [Information on the provision of public services to promote employment]. Available at: http://burzan.govrb.ru/wp-content/uploads/2015/02/2-т-РБ-за-2016-год.xls (accessed: 06.03.2018).

Rasporyazhenie Glavyi Respubliki Buryatiya No. 37-rg ot 01.07.2014 g. "Ob obespechenii potrebnosti organizatsiy $\mathrm{v}$ professionalnyih kadrah srednego i vyisshego professionalnogo obrazovaniya i trudoustroystva bezrabotnyih grazhdan v Respublike Buryatiya" [Order of the Head of the Republic of Buryatia No. 37-RG from 01.07.2014 "On ensuring the needs of organizations in the professional staff of secondary and higher professional education and employment of unemployed citizens in the Republic of Buryatia"].

Regionyi Rossii. Sotsialno-ekonomicheskie pokazateli [Regions of Russia. Socio-economic indicators]. 2017. Statistical book. - M.: Rosstat, 2017. - P. 344-442. 